\title{
RESEARCH IN IMPLEMENTATION OF AUTOMATED CONTROL SYSTEM OF CONVEYOR BELTS FROM COMBINED FEED FACTORY
}

\section{Cristian Vasile, Mihnea Glodeanu, Ion Saracin}

University of Craiova, Romania

cristi_vasile_4you@yahoo.com, mihneaglodeanu@yahoo.com, ion_saracin@yahoo.com

\begin{abstract}
Population growth in the last 20 years and also diversifying people's food needs have led to an increased demand for products obtained from animals raised on zootechnical farms. For maintaining in the profile market, by providing quality products at the lowest price, the combined feed factories were equipped with modern work equipment and installations to ensure a high degree of mechanization, automation and computerization of the activities performed. This had favourable consequences in achieving high productivity with low specific consumption. The technological flow carried out in a combined feed factory involves performing several activities, such as: supply, transport, grinding, mixing, granulation, cooling, packaging and storage. Thus, a very important activity in a combined feed factory is the transport of raw materials from warehouses to work facilities. To ensure proper functioning of work facilities and an increase of labor productivity, the implementation of automated control of conveyor belts is recommended. The experimental investigations were based on the achievement of an electronic device, through which the operation of magnetic rotation and proximity sensors was monitored. These types of sensors equip the automatic control devices for conveyor belts used in a combined feed factory. The electronic assembly realized in own conception allowed to determine with accuracy the values of the response times, as well as the distances required for automatic shutdown of the transport system. In case of overload, this automatic shutdown command is of major importance in order to avoid the destruction of the transport system. The obtained results demonstrate the functionality of the designed command and control system, as well as the need for its implementation to ensure automated monitoring of the transport of raw materials between the work facilities.
\end{abstract}

Keywords: control, conveyor belts, contactors, motors, kinematics.

\section{Introduction}

Technical progress and evolution of human society caused a radical change in the way of working in all fields of activity, so the problem of increasing the productivity of labour and also reducing the human effort became more pronounced. For this reason, there was an increase in the degree of mechanization and automation of all the activities carried out. This fact implicitly caused an increase in the complexity of the operations of manipulation, command and control of the used work installations, as well as the available artificial energy sources.

To meet these evolving requirements, a number of automated and cyber systems have been designed [1;2]. They are designed to be an intermediary between artificial energy sources and working tools or instruments used, being able at the same time to realize the command and the management of the activities in the working process for which they were implemented (Fig. 1).

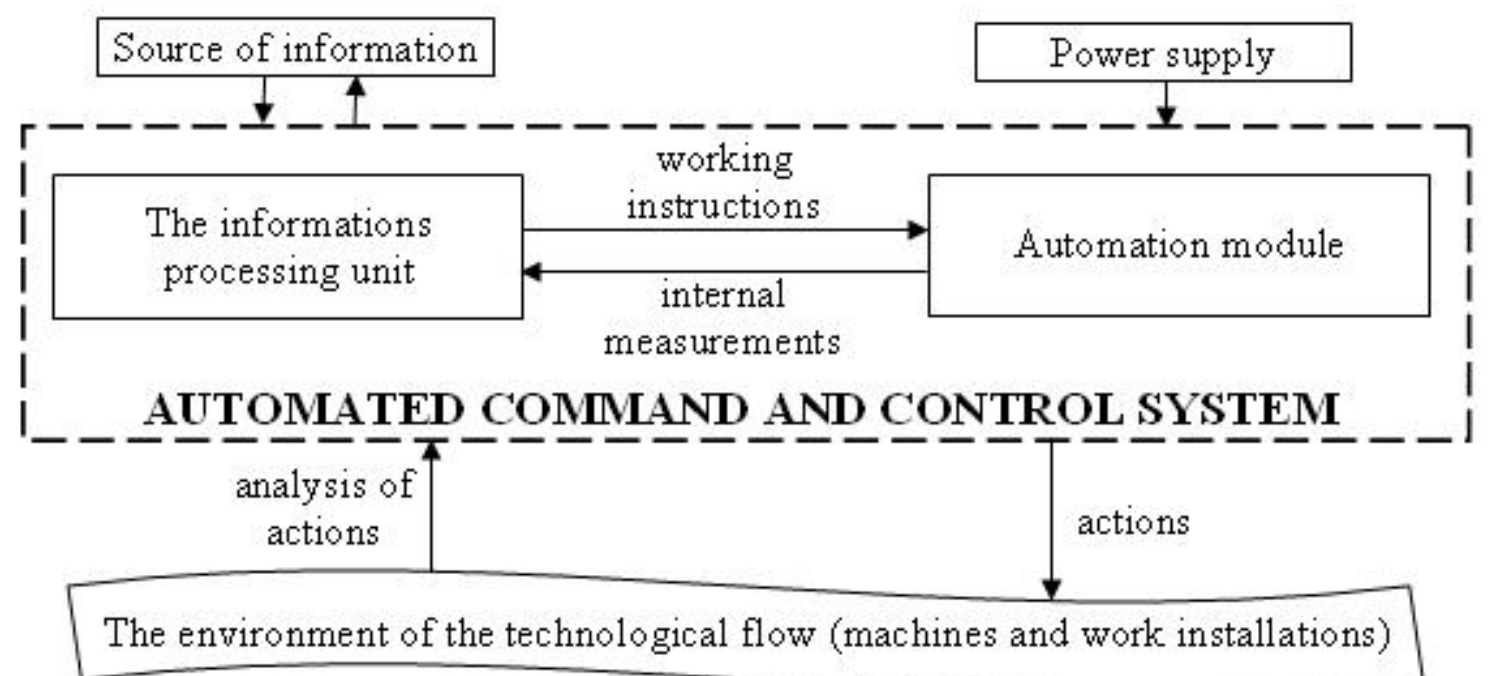

Fig. 1. Basic components of an automated system 
In a combined feed factory a series of very well-established activities are carried out, which make up the technological flow of the production process: storage, transport, grinding, dosing, mixing, granulation, cooling, packaging [1;3].

During these activities, various situations may occur that disrupt the proper development of the technological flow. Therefore, numerous analyzes and researches for the improvement of the work facilities in combined feed factories have been conducted. Thus, it has been found that certain problems may occur during the transport of raw materials from warehouses to work facilities, or during the distribution and dosing of the components (which are used to obtain different feed combinations).

Conveyor belts are used for handling raw materials both inside warehouses, as well as between the work facilities specific to the combined feed factories (CFF) $[4 ; 5]$.

This article will highlight some of the advantages of using automated command and control systems for conveyor belts of raw materials, for correct dosage of the quantities needed to prepare the desired recipes for combined feed. For the automation of these installations it is proposed to use magnetic speed and proximity sensors, and the results obtained by experimental measurements carried out will be presented in this paper.

\section{Materials and methods}

On the path of the technological flow from a combined feed factory (CFF) there are points, where the raw materials pass from one conveyor belt to another. There are also situations, when the raw materials on the conveyor belt reach into storage tanks (from the endowment of the different work installations). Thus, for various reasons overloading of conveyor belts, or accidental discharges of raw materials may occur [6]. These unwanted events may cause the displacement of the drums that support the conveyor belts, or they can block the rotational movement of the drums that drive the conveyor belts. Given that these locations are critical points of the technological flow, experimental researches were carried out that allowed the implementation of automated control devices (with the role of immediate stop so as to avoid damage or breakage of the conveyor belts) [2; 7].

A solution for the implementation of automatic control devices is the use of special magnetic sensors, to permanently monitor the optimal operation of the engines that drive the horizontal or vertical conveyor belts. Magnetic sensors are devices that allow the conversion of a non-electric input size into an electrical output size (voltage). For the two types of magnetic sensors analyzed in this paper, the non-electric input sizes are represented by the speed of rotation of a metal object, or the proximity distance to a metal body [8].

As an internal basic structure, these sensors are composed of the following component blocks (Fig. 2): sensitive coil (1); high frequency oscillator (2); bistable circuit (3); electronic demodulation block (4); signal amplifier (5); metal body that changes the length of the magnetic field lines (6).

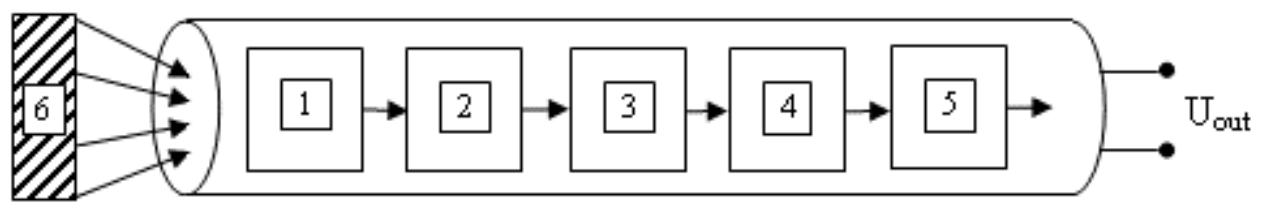

Fig. 2. Component blocks of a magnetic sensor

The operation of these sensors is done on the principle of modifying the magnetic field lines, generated by coils that are powered to a high frequency oscillator. Thus, when a metallic body approaches the sensor coils, a change in the length of the magnetic field lines emitted by these coils immediately occurs. This causes modification of the magnetic impedance of the oscillating circuit.

Automatically damping of the oscillations takes place, which determines the change of the inductivity of the magnetic circuit. This change in the operating mode will be detected by the bistable circuit (3), initially in inactive state, which switches to "1" (active) operating state. The electronic demodulation block (4) takes the signals of the bistable circuit and converts them into electrical signals, corresponding to the "0" (inactive) or " 1 " (active) states of the output size (Fig. 3). These signals can be detected by the signal amplifier (5), which will provide (through built-in circuits) the 
final value of the output size $\left(U_{\text {out }}\right)$ (Fig. 4). Thus, the signal amplifier will command the switch status or the load relay. That is why it can be considered that a magnetic sensor works as a pulse generator, whenever a metallic object passes near it.

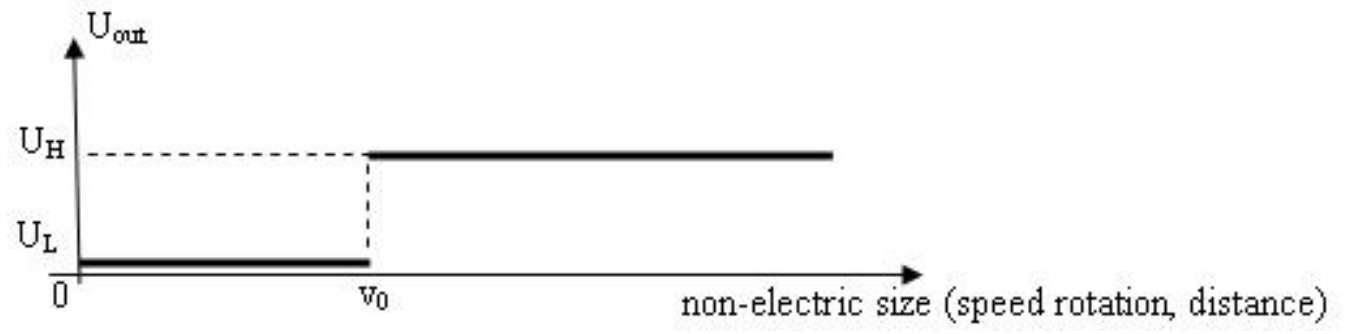

Fig. 3. Electrical output of a magnetic sensor

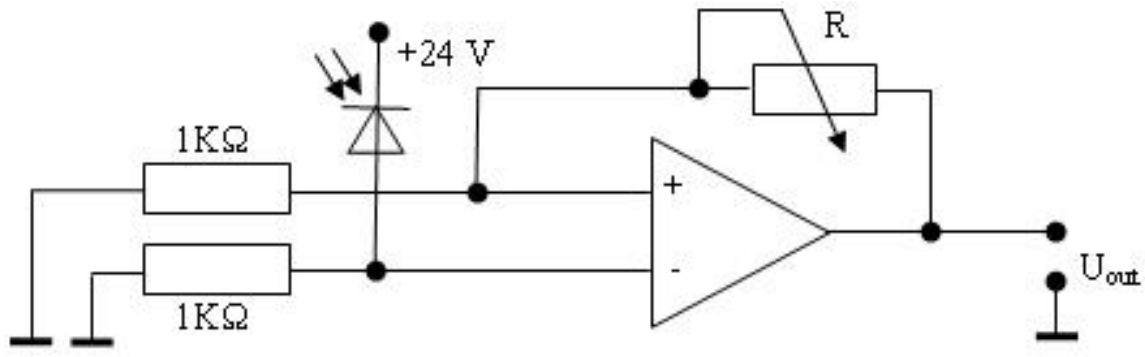

Fig. 4. Electronic circuit used to obtain the output size $\left(\boldsymbol{U}_{\text {out }}\right)$

Conveyor belts are a critical point in the technological flow of a combined feed factory, because their overload or blocking the drums (with raw materials fallen during the movement) may damage or even break them. Thus, in addition to the losses caused by the interruption of the work process, there will also be losses due to the high costs for repairing or replacing the conveyor belts $[4 ; 5]$.

In order to avoid these undesirable consequences, researches were carried out for the implementation of automated devices for controlling the operation of the conveyor belt train. This paper presents the experimental results obtained with the help of an electronic assembly (achieved in own conception), in order to study response times to different types of magnetic sensors.

The electronic assembly implemented for conducting the experimental research has the following electrical components (Fig. 5): $220 \mathrm{Vac}-24 \mathrm{Vdc}$ rectifier; motor by $80 \mathrm{~W}$ and $1500 \mathrm{rpm}$; speed of the rotation monitoring sensor; proximity sensor; two intermediate relays; $24 \mathrm{~V}$ signal lamps; voltage regulator to change the engine speed of rotation.

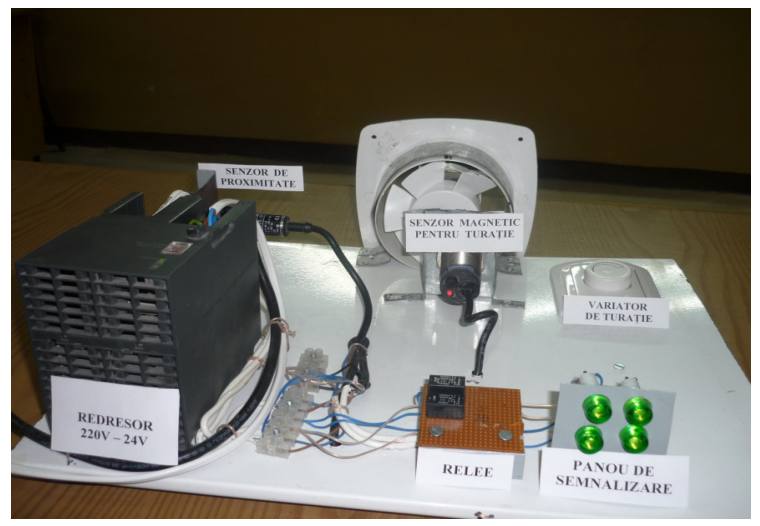

Fig. 5. Electronic assembly used to study the operation of the two types of magnetic sensors

It can be seen that there are two magnetic sensors in this assembly: one is used as a proximity sensor and indicates the presence of a metal body near it, and the other is a magnetic rotation speed sensor (which monitors the speed of rotation of a metal body attached to the engine drum). 


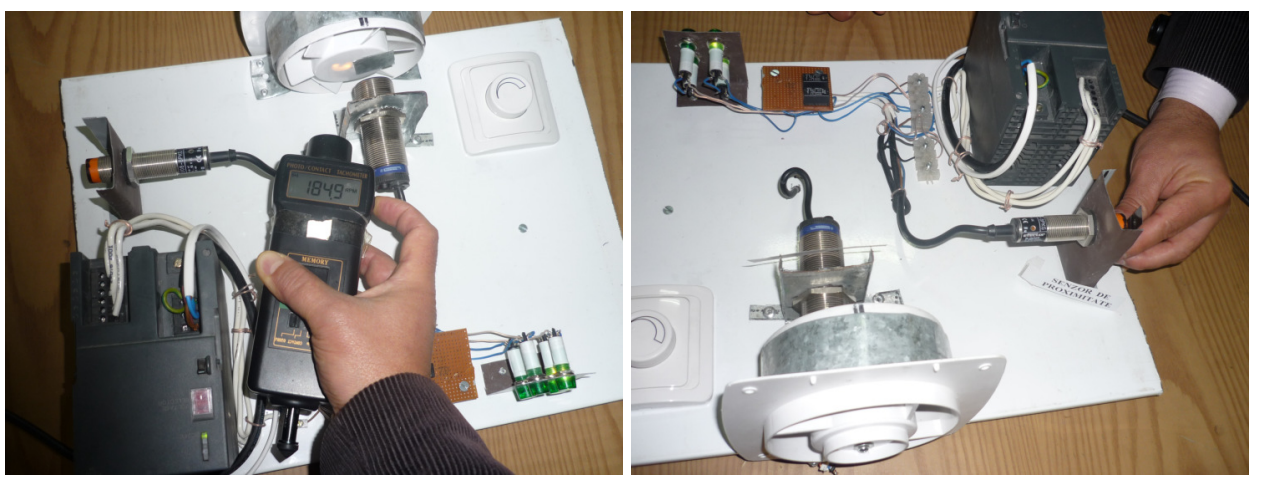

Fig. 6. Determination of the operating parameters of the magnetic sensors

An EBRO DT-2236 electronic tachometer was used to determine the speed of rotation of the metal blade attached to the drum. The sensors used in this assembly have threads on the outside and with the help of nuts the distance between the sensor and the metal body can be adjusted. Thus, the assembly is designed to measure the reaction distance for the proximity sensor, as well as the distance and speed of rotation at which the magnetic speed sensor is activated (Fig. 6).

\section{Results and discussion}

Based on the experimental measurements carried out with the help of the special assembly made in this research stage, a number of results have been obtained, regarding the operation of the different types of magnetic speed and proximity sensors.

In the case of proximity magnetic sensors, tests were performed to show how far the presence of a metallic body is detected (Table 1). Also, from these experimental measurements the distance threshold is observed, at which the metal object is no longer detected. Thus, the impulses transmitted by the sensor disappear, a fact that automatically detects the closing of the electrical circuit that controls the drive motor of the conveyor belts.

Determination of reaction distances for the proximity sensor

Table 1

\begin{tabular}{|c|c|c|c|c|c|c|c|c|c|c|c|c|c|c|c|c|}
\hline \multirow[t]{2}{*}{ Sensor model } & \multicolumn{16}{|c|}{ Experimental measurements } \\
\hline & Distance, $\mathrm{cm}$ & 0.7 & 0.8 & 1 & 1.1 & 1.2 & 1.3 & 1.4 & 1.5 & 1.6 & 1.7 & 1.8 & 1.9 & 2 & 2.1 & 2.2 \\
\hline \multirow{2}{*}{$\begin{array}{c}\text { Model } 1 \\
\text { (4B-P3004) }\end{array}$} & $\begin{array}{c}\text { Sensor } \\
\text { response }\end{array}$ & Yes & Yes & Yes & Yes & Yes & Yes & Yes & Yes & Yes & Yes & Yes & Yes & Yes & Yes & No \\
\hline & $\begin{array}{c}\text { Response } \\
\text { time, } \mathrm{s}\end{array}$ & 0.5 & 0.5 & 0.6 & 0.6 & 0.7 & 0.7 & 0.8 & 1 & 1 & 1.2 & 1.4 & 1.5 & 1.7 & 2 & - \\
\hline \multirow{3}{*}{$\begin{array}{c}\text { Model } 2 \\
\text { (LJ12A3-4-Z) }\end{array}$} & Distance, $\mathrm{cm}$ & 0.7 & 0.8 & 1 & 1.1 & 1.2 & 1.3 & 1.4 & 1.5 & 1.6 & 1.7 & 1.8 & 1.9 & 2 & 2.1 & 2.2 \\
\hline & $\begin{array}{c}\text { Sensor } \\
\text { response }\end{array}$ & Yes & Yes & Yes & Yes & Yes & Yes & Yes & Yes & Yes & Yes & Yes & Yes & Yes & Yes & No \\
\hline & $\begin{array}{l}\text { Response } \\
\text { time, s }\end{array}$ & 0.5 & 0.6 & 0.7 & 0.7 & 0.8 & 0.8 & 1 & 1 & 1 & 1.3 & 1.5 & 1.6 & 1.8 & 2.1 & - \\
\hline \multirow{3}{*}{$\begin{array}{c}\text { Model } 3 \\
(\mathrm{E} 2 \mathrm{E} 2 \mathrm{X} 2 \mathrm{Y} 1)\end{array}$} & Distance, $\mathrm{cm}$ & 0.7 & 0.8 & 1 & 1.1 & 1.2 & 1.3 & 1.4 & 1.5 & 1.6 & 1.7 & 1.8 & 1.9 & 2 & 2.1 & 2.2 \\
\hline & $\begin{array}{c}\text { Sensor } \\
\text { response }\end{array}$ & Yes & Yes & Yes & Yes & Yes & Yes & Yes & Yes & Yes & Yes & Yes & Yes & Yes & No & No \\
\hline & $\begin{array}{l}\text { Response } \\
\text { time, } s\end{array}$ & 0.6 & 0.6 & 0.7 & 0.9 & 0.9 & 1 & 1 & 1.2 & 1.4 & 1.5 & 18 & 2 & 2.2 & - & - \\
\hline
\end{tabular}

From these experimental measurements it is observed that the distance threshold, at which the metallic object is no longer detected, is around $2.1 \mathrm{~cm}$, and thus, the impulses transmitted by the sensor disappear. This automatically determines the closing of the electrical circuit, which controls the drive motor of the conveyor belts.

Fig. 7 shows the dependence of the response times on the distance between the analyzed proximity sensors and the metal body, considered as a fixed reference. 


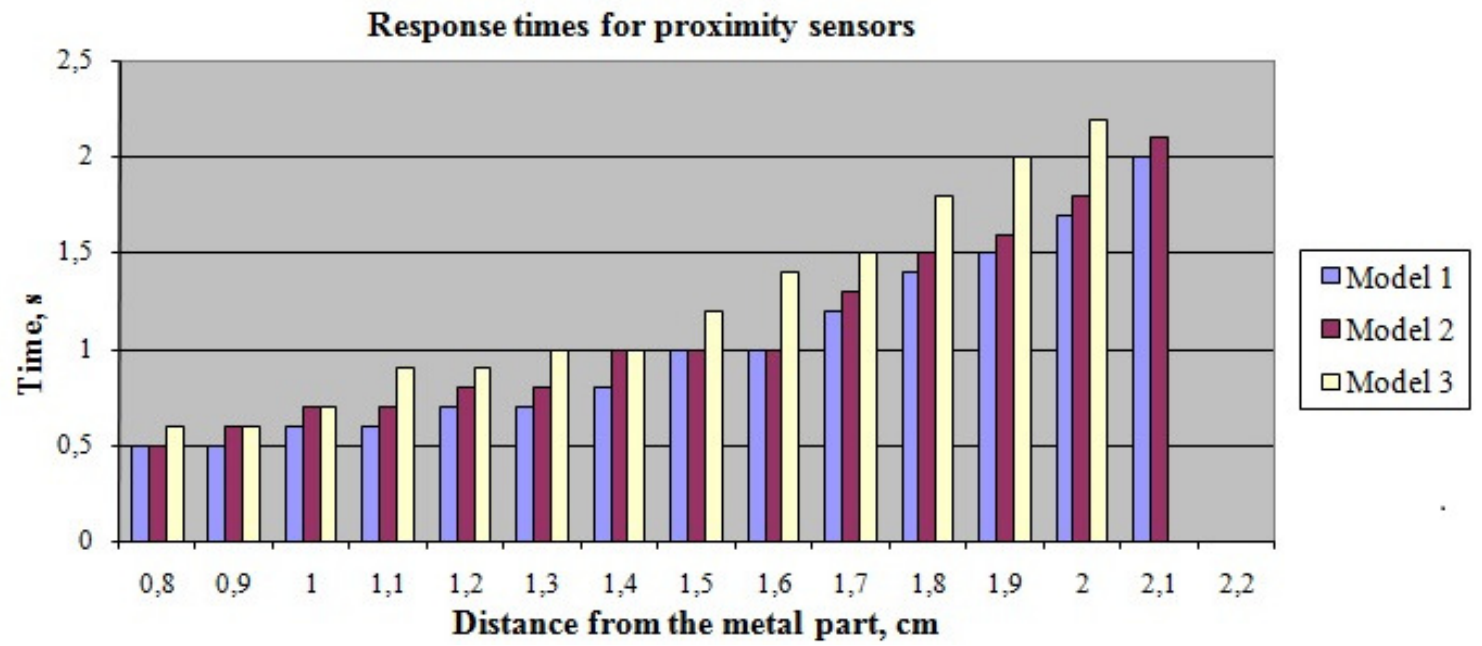

Fig. 7. Correlation of reaction times of proximity sensors with the distance to the landmark

The analysis of the graph from Figure 7 showed that the gradual change (for each $10^{-3} \mathrm{~m}$ ) of the distance between the sensor and the metal object (between $0.7 \mathrm{~cm}$ and $2.2 \mathrm{~cm}$ ) caused an increase in the response time from $0.5 \mathrm{~s}$ to over $2 \mathrm{~s}$. It is found that for the first two sensors the response limit distance is $2.1 \mathrm{~cm}$. The response time obtained for the first type of magnetic sensors recommends its use in the implementation of automated devices in combined feed factories.

For the magnetic speed sensors analyzed, experimental measurements were performed for determining the distance to which the sensor detects a rotating metal body. The response times for each type of sensors were also determined, depending on the distance at which the metal body is and its rotational speed. The results of the experimental measurements are presented in Table 2.

Table 2

Determining the characteristics of the speed of rotation monitoring sensors

\begin{tabular}{|c|c|c|c|c|c|c|c|c|c|c|c|c|c|c|c|c|c|}
\hline Sensor type & \multicolumn{17}{|c|}{ Experimental measurements } \\
\hline \multirow{4}{*}{$\begin{array}{c}\text { Type } 1 \\
(\text { LCZ460) }\end{array}$} & Distance, $\mathrm{cm}$ & 0.9 & 1 & 1.1 & 1.2 & 1.3 & 1.4 & 1.5 & 1.6 & 1.7 & 1.8 & 1.9 & 2 & 2.1 & 2.2 & 2.3 & 2.4 \\
\hline & $\begin{array}{l}\text { Rotational } \\
\text { speed, rpm }\end{array}$ & 148 & 149 & 149 & 150 & 151 & 150 & 152 & 151 & 148 & 149 & 151 & 149 & 150 & 150 & 151 & 150 \\
\hline & $\begin{array}{l}\text { Sensor } \\
\text { response }\end{array}$ & Yes & Yes & Yes & Yes & Yes & Yes & Yes & Yes & Yes & Yes & Yes & Yes & Yes & Yes & Yes & No \\
\hline & $\begin{array}{c}\text { Reaction } \\
\text { time, } s\end{array}$ & 1.6 & 2 & 2.5 & 2.8 & 3 & 3.7 & 4 & 4.2 & 4.5 & 4.8 & 5 & 5.2 & 5.7 & 5.8 & 6.1 & - \\
\hline \multirow{4}{*}{$\begin{array}{c}\text { Type } 2 \\
\text { (MSP6719) }\end{array}$} & Distance, $\mathrm{cm}$ & 0.9 & 1 & 1.1 & 1.2 & 1.3 & 1.4 & 1.5 & 1.6 & 1.7 & 1.8 & 1.9 & 2 & 2.1 & 2.2 & 2.3 & 2.4 \\
\hline & $\begin{array}{l}\text { Rotational } \\
\text { speed, rpm }\end{array}$ & 149 & 147 & 148 & 149 & 151 & 150 & 150 & 150 & 149 & 150 & 152 & 151 & 150 & 149 & 150 & 150 \\
\hline & $\begin{array}{c}\text { Sensor } \\
\text { response }\end{array}$ & Yes & Yes & Yes & Yes & Yes & Yes & Yes & Yes & Yes & Yes & Yes & Yes & Yes & Yes & Yes & No \\
\hline & $\begin{array}{c}\text { Reaction } \\
\text { time, } s\end{array}$ & 1.5 & 1.8 & 2.3 & 2.7 & 3 & 3.5 & 4 & 4 & 4.2 & 4.5 & 5 & 5 & 5.5 & 5.8 & 6 & - \\
\hline \multirow{4}{*}{$\begin{array}{c}\text { Type } 3 \\
\text { (HE950) }\end{array}$} & Distance, $\mathrm{cm}$ & 0.9 & 1 & 1.1 & 1.2 & 1.3 & 1.4 & 1.5 & 1.6 & 1.7 & 1.8 & 1.9 & 2 & 2.1 & 2.2 & 2.3 & 2.4 \\
\hline & $\begin{array}{l}\text { Rotational } \\
\text { speed, rpm }\end{array}$ & 150 & 149 & 149 & 148 & 149 & 150 & 150 & 151 & 149 & 151 & 151 & 149 & 150 & 151 & 149 & 150 \\
\hline & $\begin{array}{c}\text { Sensor } \\
\text { response }\end{array}$ & Yes & Yes & Yes & Yes & Yes & Yes & Yes & Yes & Yes & Yes & Yes & Yes & Yes & Yes & Yes & No \\
\hline & $\begin{array}{c}\text { Reaction } \\
\text { time, } \mathrm{s}\end{array}$ & 1.5 & 1.9 & 2.5 & 2.7 & 3 & 3.8 & 4 & 4.3 & 4.7 & 5 & 5.3 & 5.5 & 5.8 & 6 & 6.3 & - \\
\hline
\end{tabular}

The experimental results obtained for the three rotational speed sensors analyzed (the experimental measurements being performed for values of rotational speed of approximately $150 \mathrm{rpm}$ ) show that the distance threshold, at which the emitted signals stop, is around $2.3 \mathrm{~cm}$.

The graph in Fig. 8 shows the reaction times of the analyzed magnetic sensors, depending on the distance and speed of rotation of the metal body attached to the drum of the engine. 


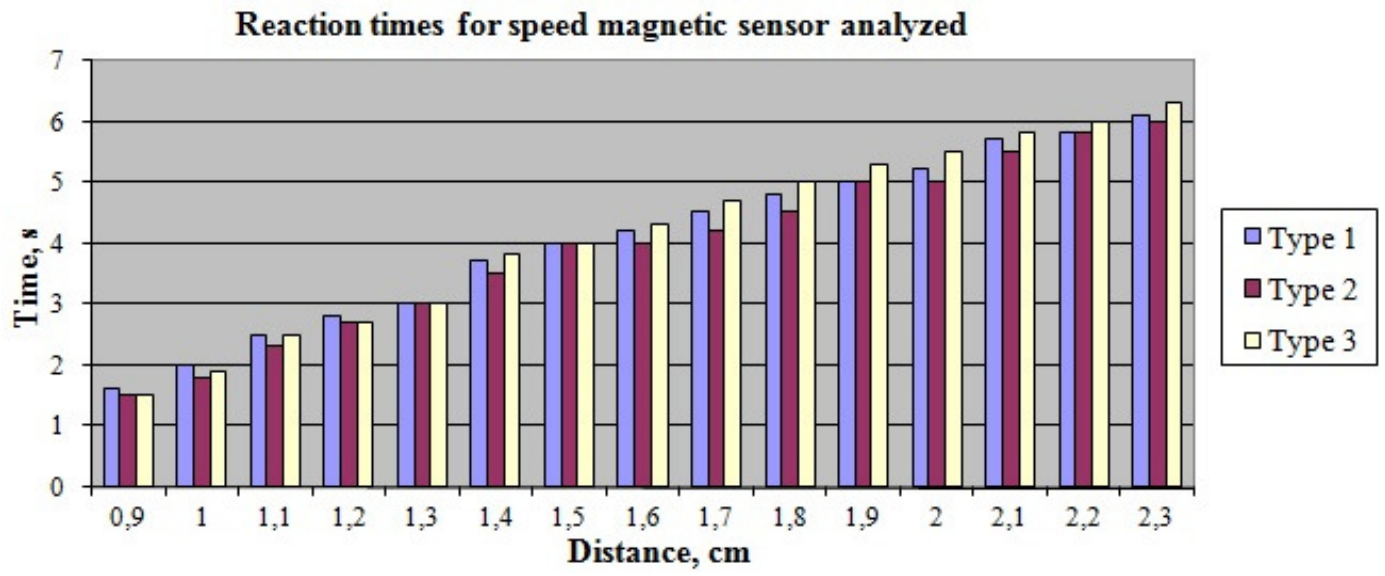

Fig. 8. Sensor reaction times depending on distance and rotational speed

\section{Conclusions}

1. The use of automated control modules ensures greater reliability of the installations serving a combined feed factory and also an increase in safety during operation, a significant increase in working efficiency, thus determining for the beneficiaries significant savings of money and time.

2. For the proximity sensors analyzed, the distance threshold, at which the metallic object is no longer detected, is around $2.1 \mathrm{~cm}$ and thus the impulses transmitted by the sensor disappear, determining the closing of the electrical circuit, which controls the drive motor of the conveyor belts; the gradual change of the distance between the sensor and the metal object, between $0.7 \mathrm{~cm}$ and $2.2 \mathrm{~cm}$, caused an increase in the response time from $0.5 \mathrm{~s}$ to over $2 \mathrm{~s}$.

3. In the case of the speed sensors analyzed, for values of the rotational speed of approximately 150 $\mathrm{rpm}$, the distance threshold, at which the emitted signals stop, is around $2.3 \mathrm{~cm}$; analysis of the reaction times of the sensors depending on distance and rotational speed showed a gradual increase in the reaction times from $1.5 \mathrm{~s}$ to a maximum acceptable value of $6.3 \mathrm{~s}$, for distances between $0.8-2.4 \mathrm{~cm}$ and for rotational speeds of the metallic landmark between $148-152 \mathrm{rpm}$.

4. These measurements recommend to use the first type of proximity sensor and the second type of speed sensor in the implementation of automated control devices in combined feed factories.

5. The obtained results support the use of speed and proximity magnetic sensors in the structure of the automatic systems of surveillance and control of the conveyor belts to achieve certain preset performances and to avoid blocking or even breaking them due to overloading with raw materials.

\section{References}

[1] Mihăilă, C. Processes and industrial installations for drying. Technical Publishing House, Bucharest, Romania, 2001, 232 p.

[2] Vasile C. The analytical and experimental modeling of functioning of automated installations from CFF. Annals of the University of Craiova - Agriculture, Montanology, Cadastre Series, Vol. XLV, no. 2, 2015, Romania, pp. 241-246.

[3] Popescu S., Ghinea T. Automation machines and equipment used in agriculture. Scrisul Romanesc Publishing House, Craiova, Romania, 1986, 371 p.

[4] Atmaca T. Approximate analysis of a conveyor system. International Journal of Production Research, vol. 32, issue 11, pp. 2645-2655, 1994.

[5] Coffman E., Gelembe E., Gilbert E.N. Analysis of a conveyor queue in a flexible manufacturing system. European Journal of Operation Research, vol. 35, issue 3, 1988, pp. 382-392.

[6] Marian O. Influence of Sieve Openings Size for Hammer Mills on the Degree of Shredding and Grinding Energy Consumption for Wheat. Bulletin of USAMV Cluj-Napoca, Vol. 70, 2013, Romania, pp. 471-472.

[7] Wang S., Guo W., Wen W., Chen R., Li T., Fang F. Research on Belt Conveyor Monitoring and Control System. ICICA, vol. 105, 2010, pp. 334-339.

[8] Brînduşa P., Iliescu C., Faur D. Mesures electriques et transducteurs. Matrix Rom Publishing House, Romania, 2006, 247 p. 